\title{
Biodegradation Behavior of Coated As-Extruded Mg-Sr Alloy in Simulated Body Fluid
}

\author{
Ming-Chun Zhao ${ }^{1}$ - Ying-Chao Zhao ${ }^{1}$. Deng-Feng Yin ${ }^{1} \cdot$ Shuo Wang ${ }^{1} \cdot$ Yong-Ming Shangguan ${ }^{2}$. Chao Liu ${ }^{1}$. \\ $\mathrm{Li}$-Li $\operatorname{Tan}^{2} \cdot \mathrm{Ci}$-Jun Shuai ${ }^{1} \cdot \mathrm{Ke} \mathrm{Yang}^{2} \cdot$ Andrej Atrens $^{3}$
}

Received: 20 September 2018 / Revised: 4 March 2019 / Published online: 10 April 2019

(c) The Chinese Society for Metals (CSM) and Springer-Verlag GmbH Germany, part of Springer Nature 2019

\begin{abstract}
As-extruded $\mathrm{Mg}-\mathrm{Sr}$ alloy, a kind of promising biodegradable biomedical material, was coated using micro-arc oxidation and also using a phosphate conversion coating. The corrosion behaviors were investigated using Hanks' solution. The corrosion of the as-extruded $\mathrm{Mg}-\mathrm{Sr}$ alloy became more serious with increasing immersion time; that is, the corrosion pits became more numerous, larger and deeper. The micro-arc oxidation coating and the phosphate conversion coating were effective in improving the corrosion resistance of the as-extruded $\mathrm{Mg}-\mathrm{Sr}$ alloy. The micro-arc oxidation coating was much more effective. Moreover, the as-extruded $\mathrm{Mg}-\mathrm{Sr}$ alloy and the coated as-extruded $\mathrm{Mg}-\mathrm{Sr}$ alloy exhibited lower corrosion rates than the as-cast $\mathrm{Mg}-\mathrm{Sr}$ alloy and the corresponding coated as-cast $\mathrm{Mg}-\mathrm{Sr}$ alloy, indicating that the corrosion properties of the coated samples are dependent on their substrates. The finer microstructure of the substrate of the as-extruded condition corroded much slower. The corrosion resistance of the coated $\mathrm{Mg}-\mathrm{Sr}$ alloy depended on the coating itself and on the microstructure of the substrate.
\end{abstract}

Keywords Mg alloy $\cdot$ Micro-arc oxidation coating $\cdot$ Phosphate conversion coating $\cdot$ Biodegradation $\cdot$ Corrosion resistance

\section{Introduction}

Magnesium $(\mathrm{Mg})$ alloys are a novel kind of biomedical material. They have potential application as biodegradable and bioresorbable bone graft substitutes due to their degradability and biocompatibility and because their mechanical properties are similar to those of bone [1-8]. Strontium $(\mathrm{Sr})$ is a necessary trace element in the human body. A moderate Sr intake may prevent arteriosclerosis and thrombosis, may promote osteoblast differentiation and bone formation, modify bone metabolism and bone mass of osteoporosis patients and may improve the mechanical properties of bone [9-12].

Available online at http://link.springer.com/journal/40195

Deng-Feng Yin

dengfeng@csu.edu.cn

1 School of Materials Science and Engineering, Central South University, Changsha 410083, China

2 Institute of Metal Research, Chinese Academy of Sciences, Shenyang 110016, China

3 Division of Materials, The University of Queensland, Brisbane, QLD 4072, Australia
Therefore, Sr has a significant potential as an alloying element in $\mathrm{Mg}$ alloy biomedical materials. Recently, $\mathrm{Mg}$ alloys alloyed with $\mathrm{Sr}$ (hereafter, $\mathrm{Mg}-\mathrm{Sr}$ alloys) have been designed for bioresorbable bone graft substitute applications [13-15]. $\mathrm{Mg}-\mathrm{Sr}$ alloys tend to contain the compounds, which segregate to grain boundaries to improve mechanical properties and corrosion resistance [16-19].

However, a potential problem for biodegradable $\mathrm{Mg}$ alloys is that rapid corrosion leads to local high alkalization and to hydrogen evolution. Accumulation of hydrogen may delay bone healing. Furthermore, the corrosion resistance of biodegradable $\mathrm{Mg}-\mathrm{Sr}$ alloys may not be sufficient for biodegradable and bioresorbable bone graft substitute applications.

The methods to control an undesirably high degradation rate include surface coatings [20,21]. The development of a biocompatible, bioactive protective coating would be an attractive way to decrease the corrosion rate of biodegradable Mg alloys. Micro-arc oxidation (MAO) coatings and chemical conversion coatings are two common coating methods that have been reported for bone repair $[14,15,21$, 22]. A MAO coating was described to decrease the corrosion rate of the $\mathrm{Mg}$ alloy, provide a better foundation for cell 
adhesion and exhibit good biocompatibility [21]. Han et al. [14] found that a MAO coating could decrease the corrosion rate of an as-cast $\mathrm{Mg}-\mathrm{Sr}$ alloy and promote bone repair. Chen et al. [22] found that a strontium phosphate ( $\mathrm{Sr}-\mathrm{P})$ conversion coating was a promising coating that could reduce the degradation rate of pure magnesium implants without adverse effects on the surrounding cells and tissue. Furthermore, a comparison of a MAO coating and a Sr-P coating on as-cast $\mathrm{Mg}-\mathrm{Sr}$ alloys has been undertaken [15].

The as-cast microstructure contains unavoidable casting defects, which may influence the service performance [23, 24], whereas the as-extruded condition may eliminate the casting defects and provide a finer grain size [25]. As a consequence, the extruded condition may be more appropriate than the as-cast condition. Also, the substrate microstructure may influence the composition and thickness of the MAO coating and its adhesion [26, 27] and influence the corrosion behavior of the coated alloy. However, the corrosion behavior of the coated as-extruded $\mathrm{Mg}-\mathrm{Sr}$ alloys is not known nor is the influence of the microstructure on the coating.

The present work studied the corrosion behavior in Hanks' solution of (1) an as-extruded $\mathrm{Mg}-\mathrm{Sr}$ alloy, (2) the as-extruded $\mathrm{Mg}-\mathrm{Sr}$ alloy with a MAO coating and (3) the as-extruded $\mathrm{Mg}-\mathrm{Sr}$ alloy with a $\mathrm{Sr}-\mathrm{P}$ coating. The corrosion behavior was characterized using in vitro immersion tests, weight loss tests, polarization curve measurements and electrochemical impedance spectroscopy (EIS). The influence of microstructure was studied before and after corrosion. These investigations are expected to obtain a better understanding of the biodegradable behavior of coated as-extruded $\mathrm{Mg}-\mathrm{Sr}$.

\section{Experimental}

The chemical composition of the as-extruded $\mathrm{Mg}-\mathrm{Sr}$ alloy was $98.5 \mathrm{wt} \% \mathrm{Mg}-1.5 \mathrm{wt} \% \mathrm{Sr}$ (hereafter, $\mathrm{Mg}-1.5 \mathrm{Sr}$ alloy). The specimens, with a dimension of $\Phi 12 \mathrm{~mm} \times 3 \mathrm{~mm}$, were mechanically ground successively with SiC emery papers of 400 grit, 800 grit, 1200 grit and 2000 grit, ultra-sonicated in acetone at room temperature for $15 \mathrm{~min}$ and washed with absolute ethanol and deionized water for $10 \mathrm{~min}$.

The MAO coating was prepared by a pulsed bipolar electrical source (WHD-20) with a power of $2 \mathrm{~kW}$ for $5 \mathrm{~min}$ at $360 \mathrm{~V}, 1 \mathrm{kHz}$ and a duty cycle of $40 \%$ as per the previous study [14]. The sample was the working electrode, and the stainless steel container was the counter electrode. The electrolyte was $8 \mathrm{~g} / \mathrm{L} \mathrm{KF} \cdot 2 \mathrm{H}_{2} \mathrm{O}, 4 \mathrm{~g} / \mathrm{L}\left(\mathrm{NaPO}_{3}\right)_{6}$ and $0.8 \mathrm{~g} / \mathrm{L}$ $\mathrm{Ca}(\mathrm{OH})_{2}$ and was kept at $20-25^{\circ} \mathrm{C}$ by a water cooling system. After the MAO treatment, each sample was rinsed thoroughly using flowing deionized water and dried using flowing air.

The Sr-P coating was a one-step conversion coating and was applied by immersing each sample in the coating solution at $80{ }^{\circ} \mathrm{C}$ for $12 \mathrm{~min}$. The coating solution contained $0.1 \mathrm{~mol} / \mathrm{L} \mathrm{Sr}\left(\mathrm{NO}_{3}\right)_{2}$ plus $0.06 \mathrm{~mol} / \mathrm{L} \mathrm{NH}_{4} \mathrm{H}_{2} \mathrm{PO}_{4}$, with the $\mathrm{pH}$ adjusted to 3.0 using dilute $\mathrm{HNO}_{3}$. The coated samples were rinsed using flowing deionized water and dried using flowing air.

The surface and cross-sectional morphologies of the coatings were examined using a scanning electron microscope (SEM), and the composition of the coatings was analyzed by energy-dispersive spectroscopy (EDS). The phase composition of the coating was characterized by $\mathrm{X}$-ray diffraction (XRD) by using $\mathrm{Cu} \mathrm{K} \alpha$ radiation with a scan range of $10-90^{\circ}$ and a scan rate of $8 \% \mathrm{~min}$.

The electrochemical tests were conducted in Hanks' solution $\left(8 \mathrm{~g} / \mathrm{L} \mathrm{NaCl}, 0.4 \mathrm{~g} / \mathrm{L} \mathrm{KCl}, 0.06 \mathrm{~g} / \mathrm{L} \mathrm{KH}_{2} \mathrm{PO}_{4}\right.$, $0.12 \mathrm{~g} / \mathrm{L} \mathrm{Na} \mathrm{NPO}_{4}, 0.14 \mathrm{~g} / \mathrm{L} \mathrm{CaCl}_{2}, 0.2 \mathrm{~g} / \mathrm{L} \mathrm{MgSO}$ $7 \mathrm{H}_{2} \mathrm{O}, 0.35 \mathrm{~g} / \mathrm{L} \mathrm{NaHCO}{ }_{3}, 1 \mathrm{~g} / \mathrm{L}$ glucose, $\mathrm{pH}=7.4$ ) at $37.0 \pm 0.5^{\circ} \mathrm{C}$ using an electrochemical work station (Reference 60 , Gamry, USA). A three-electrode cell had the pre-treated sample as the working electrode, a platinum plate as the counter electrode and a saturated calomel electrode (SCE) as a reference electrode. The area exposed to the Hanks' solution was $1.65 \mathrm{~cm}^{2}$. Potentiodynamic polarization tests were measured at a scanning rate of $0.5 \mathrm{mV} / \mathrm{s}$ after exposure for $30 \mathrm{~min}$ at the open circuit potential (OCP). The values of the corrosion current density $\left(i_{\text {corr }}\right.$ $\left.\mathrm{mA} \mathrm{cm}{ }^{-2}\right)$ were converted to the corrosion rates $P_{i}(\mathrm{~mm} /$ year), using the following [24]:

$P_{i}=22.85 i_{\text {corr }}$.

The frequency range of $100 \mathrm{kHz}$ to $0.01 \mathrm{~Hz}$ was used for the electrochemical impedance spectroscopy (EIS). The data were analyzed using the Gamry Echem Analyst software. Six identical samples were tested to check repeatability. Immersion tests were conducted using Hanks' solution at $37.5 \pm 0.5^{\circ} \mathrm{C}$ for 14 days with an immersion ratio of $1.25 \mathrm{~cm}^{2} / \mathrm{mL}$. The immersion solution was refreshed every day. The $\mathrm{pH}$ variation was measured every $24 \mathrm{~h}$ during the immersion test and $24 \mathrm{~h}$ after the solution had been refreshed. The cross-sectional morphologies of different coatings after immersion for 7 and 14 days were analyzed by SEM and EDS. The corrosion rate was evaluated from the weight loss after immersion for 3, 7 and 14 days. The initial mass of the samples of $\mathrm{Mg}-1.5 \mathrm{Sr}$ alloy before coating was weighed. The chromic acid solution $\left(200 \mathrm{~g} / \mathrm{L} \mathrm{CrO}_{3}\right.$ and $10 \mathrm{~g} / \mathrm{L}_{\mathrm{AgNO}_{3}}$ ) was used for $15 \mathrm{~min}$ in an ultrasonic bath at room temperature to remove the corrosion product and the coating. The corrosion rate was calculated according to ASTM G31-72 using the following equation:

$C=K W / A T D$,

where $C$ is corrosion rate ( $\mathrm{mm} / \mathrm{year}), K$ is a constant, $8.76 \times 10^{4}, W$ is the mass loss $(\mathrm{g}), A$ is surface area $\left(\mathrm{cm}^{2}\right), T$ 
is the time of exposure (h) and $D$ is the density of material $\left(\mathrm{g} / \mathrm{cm}^{3}\right)$.

\section{Results}

\subsection{Microstructure}

Figure 1a presents the optical micrograph of the as-extruded $\mathrm{Mg}-1.5 \mathrm{Sr}$ alloy. The microstructure of the as-extruded $\mathrm{Mg}$ $1.5 \mathrm{Sr}$ alloy typically contains a matrix of $\alpha-\mathrm{Mg}$ grains, and the second-phase particles discontinuously distributed along the $\alpha-\mathrm{Mg}$ grain boundaries. The average grain size of the as-extruded $\mathrm{Mg}-1.5 \mathrm{Sr}$ alloy was about $20 \mu \mathrm{m}$. The $\mathrm{Mg}-\mathrm{Sr}$ binary equilibrium phase diagram indicates that during cooling, the liquid solidifies into eutectic $\alpha-\mathrm{Mg}$ grains and eutectic phase $\mathrm{Mg}_{17} \mathrm{Sr}_{12}$ by a eutectic reaction at the eutectic temperature of $587^{\circ} \mathrm{C}$ when the $\mathrm{Sr}$ contents is below $10 \mathrm{wt} \%$ [28]. The XRD pattern of the as-extruded $\mathrm{Mg}-1.5 \mathrm{Sr}$ alloy is exhibited in Fig. 1c, in which only the $\mathrm{Mg}$ and $\mathrm{Mg}_{17} \mathrm{Sr}_{12}$ phases were detected. This was in good agreement with the above analysis from the $\mathrm{Mg}-\mathrm{Sr}$ equilibrium phase diagram. Therefore, according to the XRD pattern and the $\mathrm{Mg}-\mathrm{Sr}$ binary phase diagram, the $\mathrm{Mg}_{17} \mathrm{Sr}_{12}$ intermetallic is the only precipitated phase in the $\mathrm{Mg}-1.5 \mathrm{Sr}$ alloy.

Comparatively, Fig. 1c presents the optical micrograph of the original as-cast $\mathrm{Mg}-1.5 \mathrm{Sr}$ alloy, which was used to produce the present as-extruded $\mathrm{Mg}-1.5 \mathrm{Sr}$ alloy. The microstructure of the original as-cast $\mathrm{Mg}-1.5 \mathrm{Sr}$ alloy consisted of the primary a-Mg matrix and intermetallic second-phase precipitations. The intermetallic second-phase precipitations were located clearly along the boundaries of the a-Mg grains, showing a somewhat netlike distribution that was somewhat continuous. The average grain size of the original as-cast $\mathrm{Mg}-1.5 \mathrm{Sr}$ alloy was about $100 \mu \mathrm{m}$. Note that different from the original as-cast $\mathrm{Mg}-1.5 \mathrm{Sr}$ alloy, the as-extruded $\mathrm{Mg}-1.5 \mathrm{Sr}$ alloy has a much finer grain size and the broken discontinuous second-phase particles distributed along grain boundaries, showing a characteristic of a deformed microstructure.

\subsection{Composition of the Coatings}

Figure 2 shows the representative morphologies, corresponding to the surface and the cross section of the MAO coating and the $\mathrm{Sr}-\mathrm{P}$ coating on the as-extruded $\mathrm{Mg}-1.5 \mathrm{Sr}$ alloy, respectively. Figure 2a shows that the surface of the MAO coating was smooth, uniform, and contained many micro-pores and micro-cracks, typical of a MAO coating. Figure $2 b$ shows that the cross section of the MAO coating contained an inner compact layer and an outer porous layer, with a total thickness of $13 \mu \mathrm{m}$ to $18 \mu \mathrm{m}$. The red marks indicate the internal dense layer exhibiting a good binding between the coating and the substrate. The white arrow points to an intermetallic phase particle in the $\mathrm{Mg}$ alloy. The potential of the second-phase particles is typically higher than that of matrix. When the $\mathrm{Mg}-1.5 \mathrm{Sr}$ alloy was exposed to the corrosion environment, galvanic corrosion preferentially occurred at the matrix adjacent to the second phase. Figure 2c shows that the morphology of the $\mathrm{Sr}-\mathrm{P}$ coating, which was heterogeneous. The surface of $\mathrm{Mg}-1.5 \mathrm{Sr}$ substrate was fully covered with the crystals in a staggered flaky arrangement. Furthermore, the deposition flakes were interlocked together, and accordingly, the whole coating was fixed on the substrate firmly. Figure $2 \mathrm{~d}$ shows the crosssectional morphology of $\mathrm{Sr}-\mathrm{P}$ coating. The $\mathrm{Sr}-\mathrm{P}$ coating was uniform with thickness of 25-40 $\mu \mathrm{m}$, and had evidently good binding with the substrate.

EDS analysis as shown in Fig. 3 was used to evaluate the elemental compositions of the coatings. The surface and cross section of MAO coating were both mainly composed of $\mathrm{O}, \mathrm{F}, \mathrm{Ca}, \mathrm{P}$ and $\mathrm{Mg}$ (Fig. 3a, b). The $\mathrm{K}$ was the residual $\mathrm{K}$ from the Hanks' solution. The surface of the $\mathrm{Sr}-\mathrm{P}$ coating was mainly composed of $\mathrm{O}, \mathrm{P}, \mathrm{Sr}$ and $\mathrm{Mg}$ (Fig. 3c). The elements $\mathrm{Sr}$ and $\mathrm{P}$ were mainly distributed in the outer side of the coatings. The cross section of $\mathrm{Sr}-\mathrm{P}$ coating contained $\mathrm{O}, \mathrm{P}, \mathrm{Sr}$ and $\mathrm{Mg}$ (Fig. 3d). Compared with the compositions
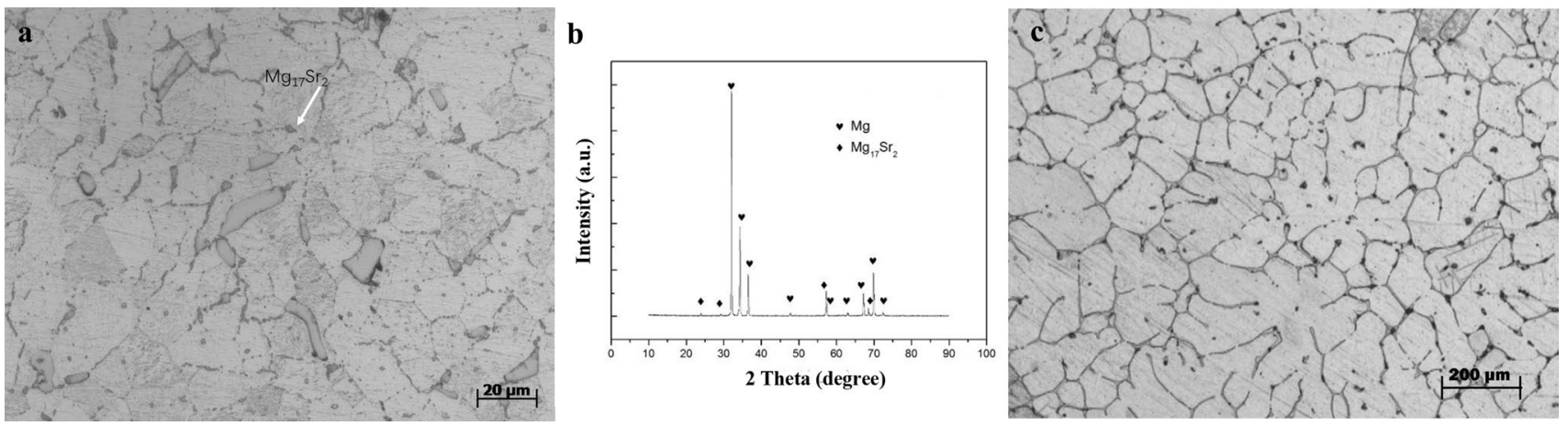

Fig. 1 Optical micrograph a, XRD pattern $\mathbf{b}$ of as-extruded $\mathrm{Mg}-1.5 \mathrm{Sr}$ alloy, and optical micrograph $\mathbf{c}$ of original as-cast $\mathrm{Mg}-1.5 \mathrm{Sr}$ alloy 

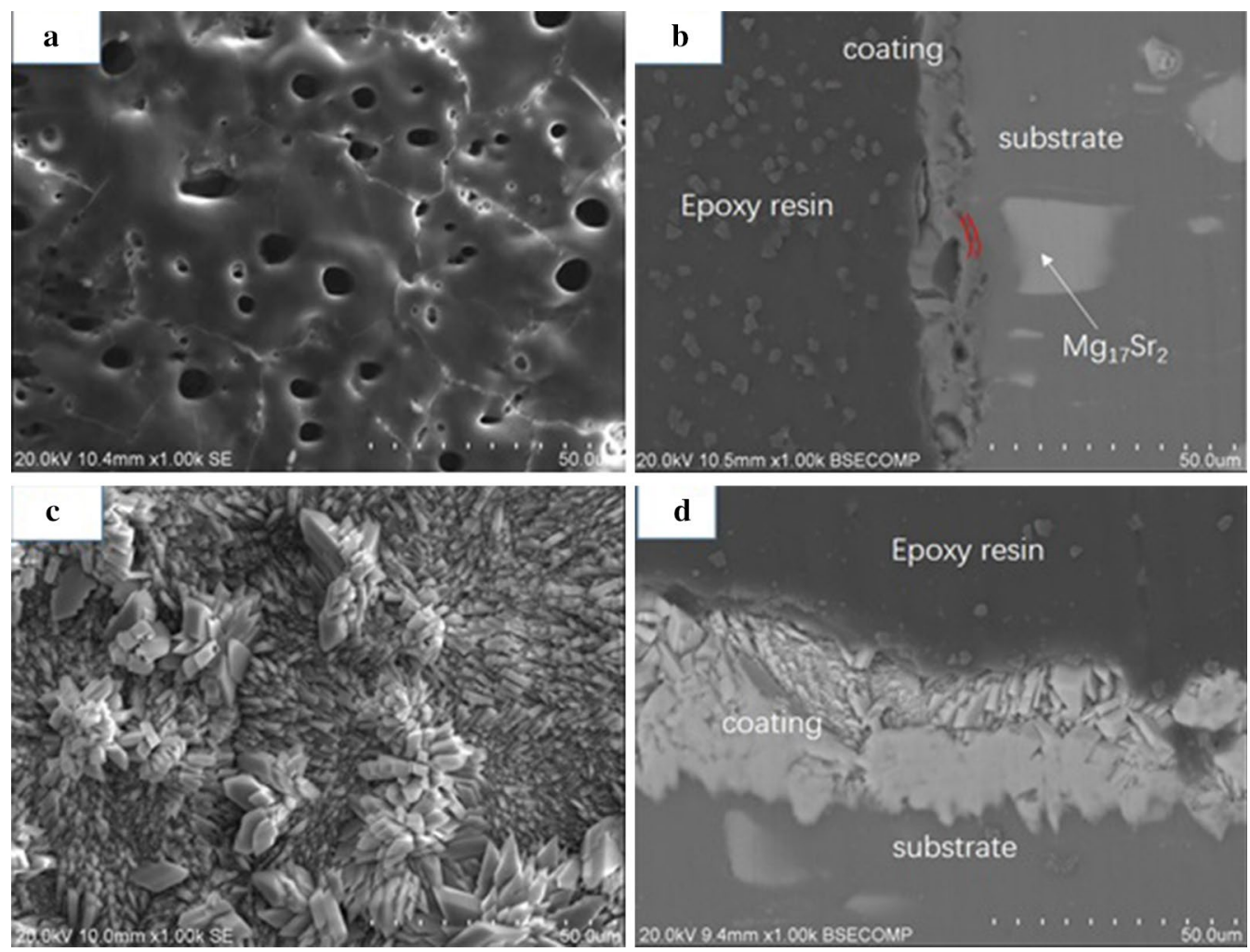

Fig. 2 Surface and cross-sectional morphologies of MAO coating (a surface, $\mathbf{b}$ cross section) and Sr-P coating (c surface $\mathbf{d}$ cross section)
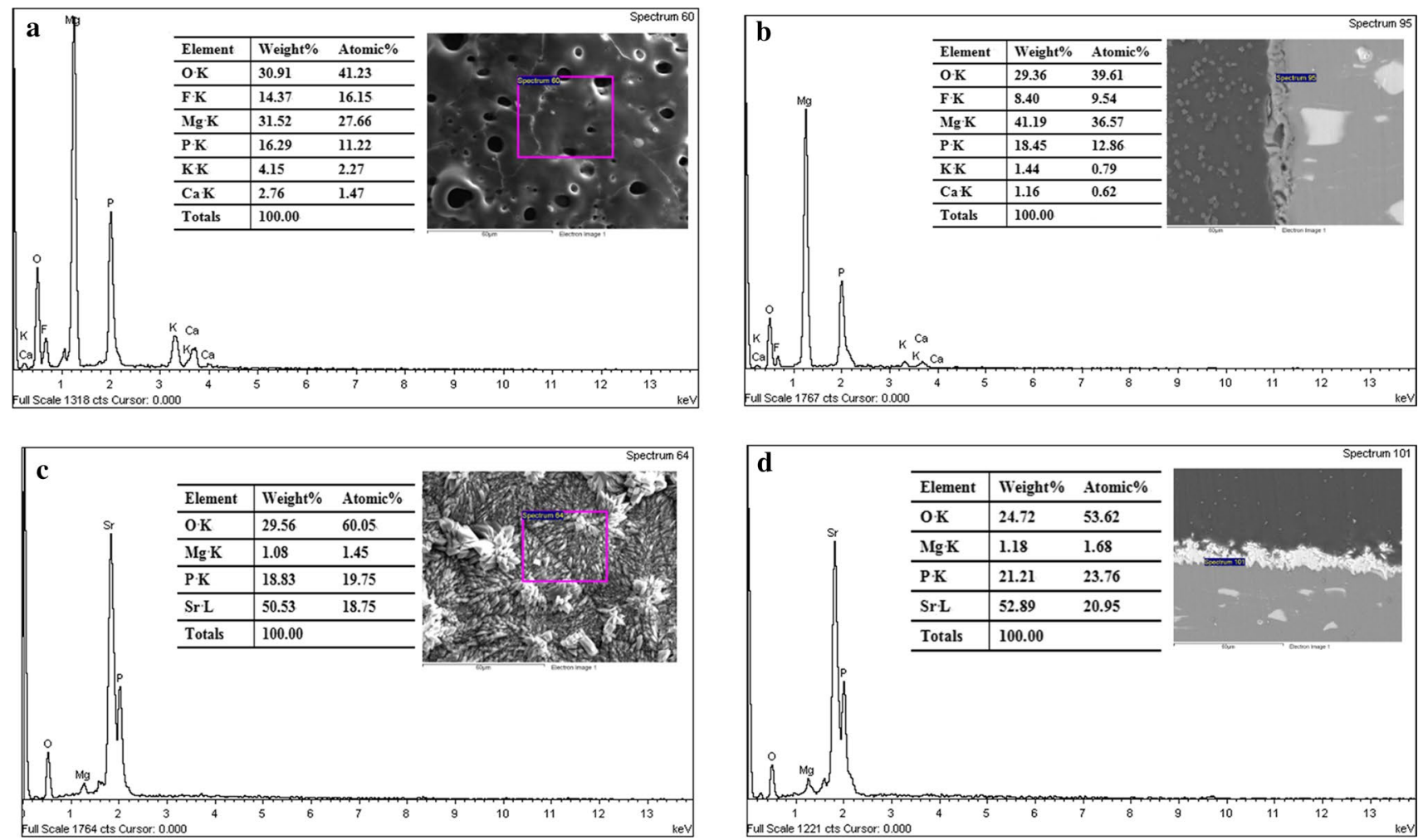

Fig. 3 EDS spectra of surface and cross section for MAO coating (a surface, $\mathbf{b}$ cross section) and $\mathrm{Sr}-\mathrm{P}$ coating (c surface, $\mathbf{d}$ cross section) 
of $\mathrm{Sr}-\mathrm{P}$ coating, the content of $\mathrm{Mg}$ of the MAO coating was much higher, due to the contribution from the Mg alloy substrate. To allow easy comparison, Table 1 presents the average chemical compositions obtained from at least three spot sites using EDS of the surface and the cross section for the coatings.

Figure 4 shows XRD patterns taken from the coatings. There were only small peaks corresponding to $\mathrm{MgO}$ (Fig. 4a). Phases containing $\mathrm{Ca}$ and $\mathrm{P}$ were not detected in the MAO coating, although some $\mathrm{Ca}$ and $\mathrm{P}$ elements were detected in the EDS analyses (Table 1), indicating that $\mathrm{Ca}$ and $\mathrm{P}$ were probably in the form of an amorphous state, which was related to the quick-cooling of the MAO coating [29]. Figure $4 \mathrm{~b}$ shows XRD pattern of the $\mathrm{Sr}-\mathrm{P}$ coating, which contained $\mathrm{SrHPO}_{4}$ and $\mathrm{Mg}_{3}\left(\mathrm{PO}_{4}\right)_{2}$.

\subsection{Electrochemical Evaluation}

Figure 5a shows the polarization curves of the different coatings and the as-extruded $\mathrm{Mg}-1.5 \mathrm{Sr}$ substrate. The Tafel fitting data yielded values for the corrosion current density $\left(I_{\text {corr }}\right)$, corrosion potential $\left(E_{\text {corr }}\right)$ and corrosion rate $(C)$.
The values are presented in Table 2. The anodic polarization curves represent the dissolution of magnesium, and the cathodic polarization curves represent the hydrogen evolution [30, 31]. The presence of the coating decreased both the anodic reaction and the cathodic reaction rate. The anodic and cathodic branches in the polarization curves were not symmetrical. The corrosion rate was evaluated from the polarization curves by Tafel extrapolation using the cathodic branch. The anodic branch was not used. The non-symmetrical polarization curve between the anodic and cathodic branches was related to the complicated anodic polarization behavior of $\mathrm{Mg}$ alloys. The surface film in the anodic range was imperfect. Some areas were broken, and the substrate metal was exposed to the solution directly. Two potential reasons for the complicated nature of the anodic polarization curves were: (1) simultaneous combination of both anodic dissolution and cathodic hydrogen evolution in the anodic region; and (2) occurrence of localized corrosion, which resulted in the anodic process being unstable. The corrosion current density and the corrosion rate of the MAO coating, the $\mathrm{Sr}-\mathrm{P}$ coating and the as-extruded $\mathrm{Mg}-1.5 \mathrm{Sr}$ substrate measured from the cathodic branch of polarization
Table 1 Chemical composition of the surface and the cross section for the coatings

\begin{tabular}{lllllllll}
\hline Coating & & $\mathrm{Mg}$ & $\mathrm{O}$ & $\mathrm{F}$ & $\mathrm{P}$ & $\mathrm{K}$ & $\mathrm{Ca}$ & $\mathrm{Sr}$ \\
\hline MAO surface & wt\% & $32 \pm 2$ & $31 \pm 2$ & $15 \pm 1$ & $16 \pm 1$ & $4.3 \pm 0.2$ & $2.5 \pm 0.2$ & \\
& at. $\%$ & $28 \pm 2$ & $41 \pm 3$ & $17 \pm 1$ & $11 \pm 1$ & $2.2 \pm 0.1$ & $1.6 \pm 0.1$ & \\
MAO cross section & wt\% & $42 \pm 2$ & $29 \pm 2$ & $8.5 \pm 0.3$ & $18 \pm 1$ & $1.4 \pm 0.1$ & $1.2 \pm 0.1$ & \\
& at. $\%$ & $37 \pm 2$ & $40 \pm 2$ & $9.5 \pm 0.2$ & $13 \pm 1$ & $0.8 \pm 0.1$ & $0.6 \pm 0.1$ & \\
Sr-P-surface & wt\% & $1.1 \pm 0.1$ & $30 \pm 1$ & & $18 \pm 1$ & & & $51 \pm 3$ \\
& at.\% & $1.5 \pm 0.1$ & $60 \pm 3$ & & $20 \pm 1$ & & & $19 \pm 1$ \\
Sr-P-cross section & wt\% & $1.2 \pm 0.1$ & $25 \pm 2$ & & $21 \pm 1$ & & & $53 \pm 3$ \\
& at.\% & $1.6 \pm 0.1$ & $54 \pm 3$ & & $24 \pm 1$ & & & $21 \pm 1$ \\
\hline
\end{tabular}

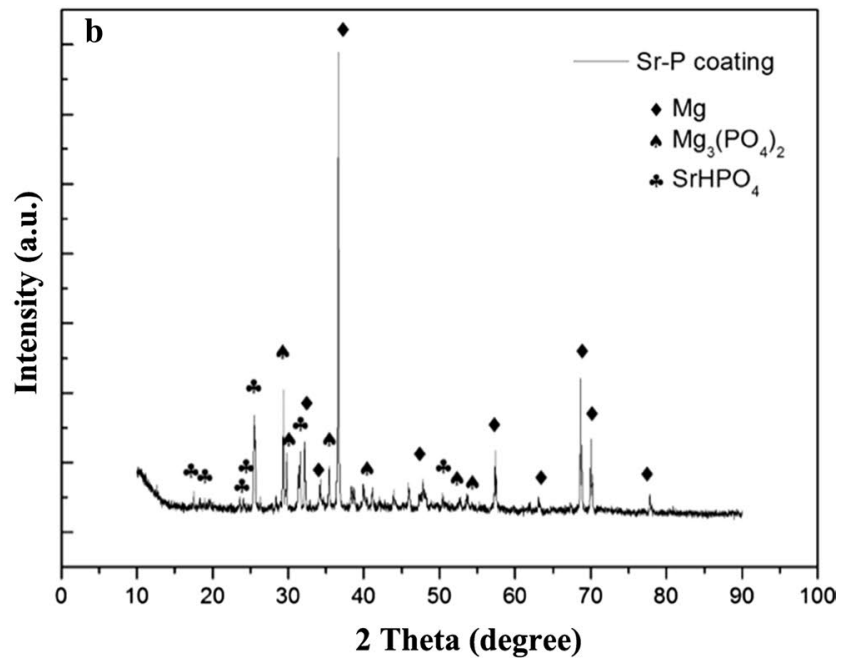

Fig. 4 XRD patterns of a MAO coating, $\mathbf{b} \mathrm{Sr}-\mathrm{P}$ coating 

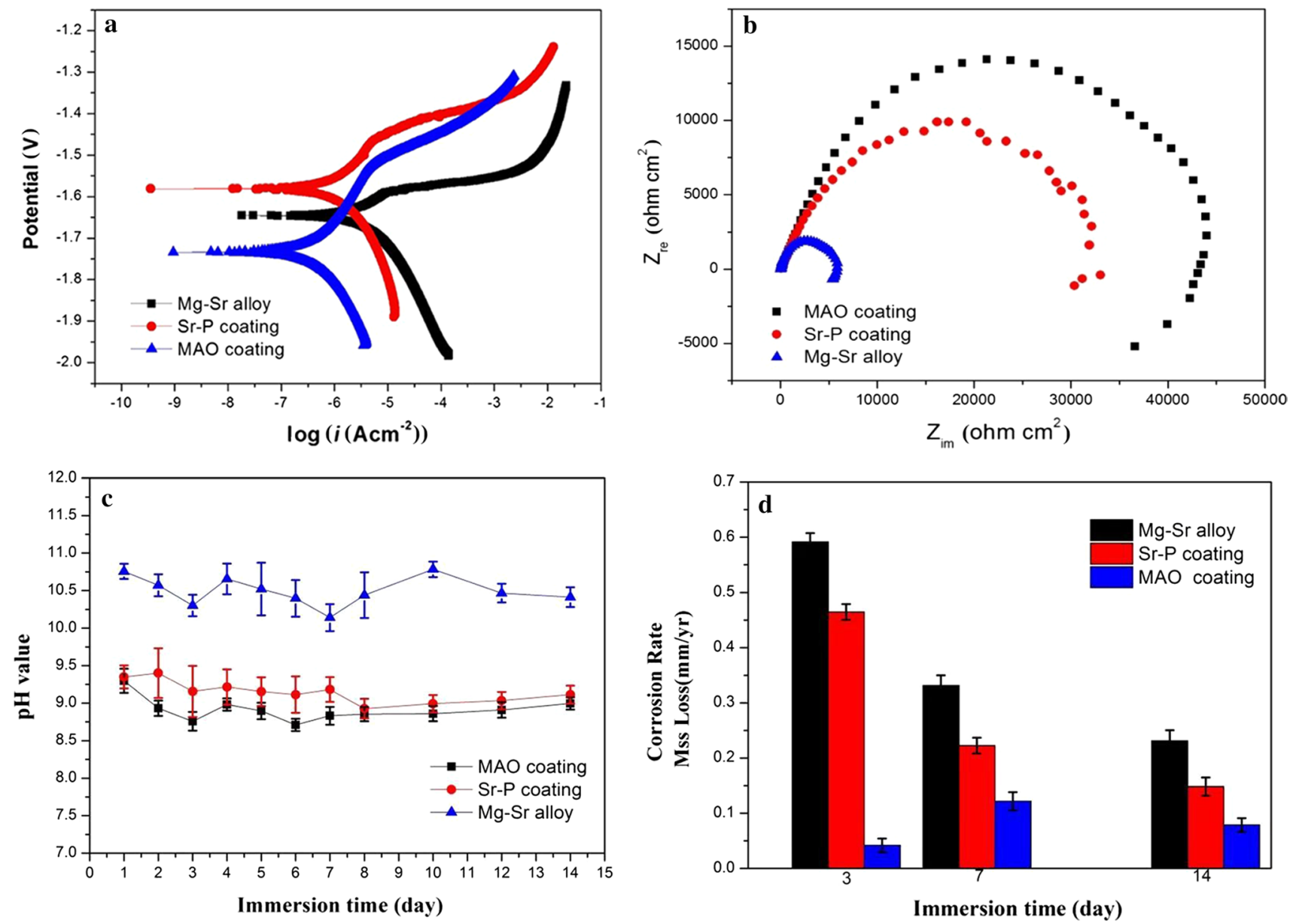

Fig. 5 Potentiodynamic polarization curves a, Nyquist plots $\mathbf{b}, \mathrm{pH}$ variation $\mathbf{c}$, corrosion rate calculated by mass loss $\mathbf{d}$ of different coatings and as-extruded $\mathrm{Mg}-1.5 \mathrm{Sr}$ substrate immersed in Hank's solution

Table 2 Electrochemical parameters fitted from the polarization curves of as-extruded condition

\begin{tabular}{llll}
\hline As-extruded condition & $I_{\text {corr }}\left(\mu \mathrm{A} / \mathrm{cm}^{2}\right)$ & $E_{\text {corr }}(\mathrm{V} / \mathrm{SCE})$ & $C(\mathrm{~mm} / \mathrm{y})$ \\
\hline Mg-1.5Sr substrate & 4.1 & -1.64 & 0.09 \\
Sr-P coating & 1.5 & -1.58 & 0.03 \\
MAO coating & 0.5 & -1.73 & 0.01 \\
\hline
\end{tabular}

curves are shown in Table 2. To allow easy comparison, the polarization curves and the corresponding corrosion current density and corrosion rate of the as-cast $\mathrm{Mg}-1.5 \mathrm{Sr}$ substrate and its different coatings are shown in Fig. 6a and Table 3, respectively.

The corrosion current densities of both the MAO coating and the $\mathrm{Sr}-\mathrm{P}$ coating were somewhat lower than those of the corresponding substrate for the as-extruded condition and the as-cast condition, indicating that both MAO coating and $\mathrm{Sr}-\mathrm{P}$ coating provided some protection, i.e., the most likely effect is that the coating acted as a barrier to corrosion when the substrate was covered by the coating. The corrosion rate of MAO coating was lower than those of $\mathrm{Sr}-\mathrm{P}$ coating and of the bare substrate, indicating a somewhat better corrosion resistance of the MAO coating compared with the $\mathrm{Sr}-\mathrm{P}$ coating. Moreover, the as-cast $\mathrm{Mg}-\mathrm{Sr}$ alloy and the coated as-cast $\mathrm{Mg}-\mathrm{Sr}$ alloy exhibit a corrosion current density higher than the as-extruded $\mathrm{Mg}-\mathrm{Sr}$ alloy and the corresponding coated as-extruded $\mathrm{Mg}-\mathrm{Sr}$ alloy, indicating that the corrosion properties of the coated samples are dependent on their substrates.

The electrochemical impedance spectroscopy (EIS) technique was used to further investigate the corrosion behavior. Figure $5 \mathrm{~b}$ presents the Nyquist plots of the two coated Mg$1.5 \mathrm{Sr}$ alloys and the bare as-extruded $\mathrm{Mg}-1.5 \mathrm{Sr}$ substrate. Makar et al. [32] found that the diameter of the capacitive semicircle of Nyquist plots was related to the corrosion rate. The MAO coating exhibited the largest size of the capacitive loops, the $\mathrm{Sr}-\mathrm{P}$ coating was in a second position, and the as-extruded $\mathrm{Mg}-1.5 \mathrm{Sr}$ substrate was relatively the smallest, indicating that the MAO coating had the highest corrosion 

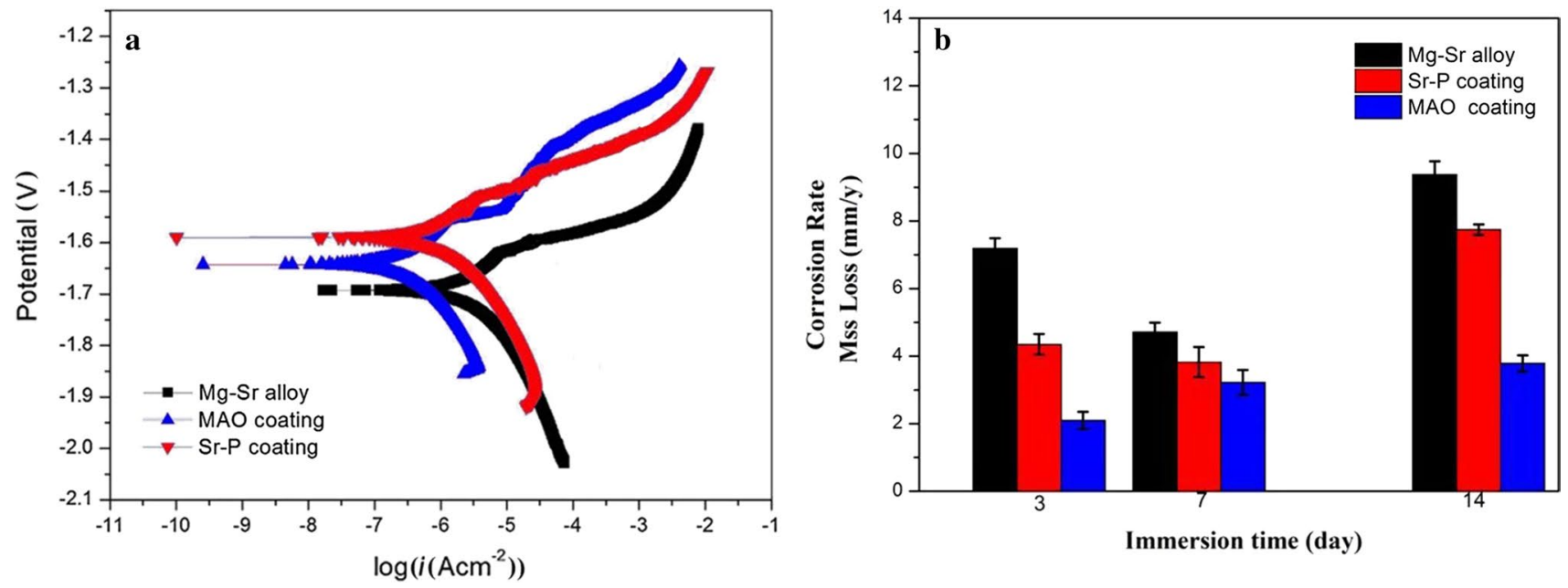

Fig. 6 Potentiodynamic polarization curves a, corrosion rate calculated by mass loss $\mathbf{b}$ of different coatings and as-cast $\mathrm{Mg}-1.5 \mathrm{Sr}$ substrate immersed in Hank's solution

Table 3 Electrochemical parameters fitted from the polarization curves of as-cast condition

\begin{tabular}{llll}
\hline As-cast condition & $I_{\text {corr }}\left(\mu \mathrm{A} / \mathrm{cm}^{2}\right)$ & $E_{\text {corr }}(\mathrm{V} / \mathrm{SCE})$ & $C(\mathrm{~mm} / \mathrm{y})$ \\
\hline Mg-1.5Sr substrate & 5.6 & -1.69 & 0.13 \\
Sr-P coating & 1.7 & -1.59 & 0.04 \\
MAO coating & 0.8 & -1.65 & 0.02 \\
\hline
\end{tabular}

resistance compared with the $\mathrm{Sr}-\mathrm{P}$ coating and the asextruded $\mathrm{Mg}-1.5 \mathrm{Sr}$ substrate.

\subsection{Immersion Tests}

Immersion tests were used to evaluate the long-term corrosion behavior of the MAO coating, the $\mathrm{Sr}-\mathrm{P}$ coating and the as-extruded $\mathrm{Mg}-1.5 \mathrm{Sr}$ substrate. Figure $5 \mathrm{c}$ shows the variation of the $\mathrm{pH}$ value of the as-extruded $\mathrm{Mg}-1.5 \mathrm{Sr}$ alloy with the two coatings and the as-extruded $\mathrm{Mg}-1.5 \mathrm{Sr}$ substrate during immersion in Hanks' solution for 14 days. The $\mathrm{pH}$ value of the Hanks' solution was in all cases higher than the initial $\mathrm{pH}$ of Hanks' solution of 7.3. The $\mathrm{pH}$ of the Hanks' solution with immersed coated samples was lower than those of the bare as-extruded $\mathrm{Mg}-1.5 \mathrm{Sr}$ samples at all time points. The lower $\mathrm{pH}$ value indicates a lower corrosion rate of the alloy or the surface coating [33, 34]. At most of the time points, the order of the $\mathrm{pH}$ values was $\mathrm{Mg}-1.5 \mathrm{Sr}$ substrate $>\mathrm{Sr}-\mathrm{P}$ coating $>$ MAO coating, which indicated that these two coatings had lower corrosion rates than that of the as-extruded $\mathrm{Mg}-1.5 \mathrm{Sr}$ alloy. Furthermore, the protection effect of MAO coating was superior to that of the $\mathrm{Sr}-\mathrm{P}$ coating. The $\mathrm{pH}$ value for the non-coated as-extruded $\mathrm{Mg}-\mathrm{Sr}$ alloy increased rapidly to 10.8 after the first day of immersion and then fluctuated between 10 and 11 . This was attributed to the low solubility of $\mathrm{Mg}(\mathrm{OH})_{2}$. After 12 days of immersion, the $\mathrm{pH}$ value was 10.5. Comparatively, the $\mathrm{pH}$ value for the MAO coating increased rapidly to 9.3 during the first day of immersion and was approximately constant at 9.0 thereafter. The $\mathrm{pH}$ value for $\mathrm{Sr}-\mathrm{P}$ coating increased to 9.4 in the first day and was approximately constant at 9.3 until the seventh day and then at 9.1 thereafter.

The corrosion rate $(C)$ evaluated from weight loss measurement after immersion of 3, 7 and 14 days is presented in Fig. 5d. The MAO-coated samples exhibited the lowest corrosion rate at every time point (3, 7, or 14 days), followed by the Sr-P coated samples, and then the as-extruded $\mathrm{Mg}-1.5 \mathrm{Sr}$ substrate samples, which indicates the MAO coating provided the best corrosion protection, followed by the $\mathrm{Sr}-\mathrm{P}$ coating and the as-extruded $\mathrm{Mg}-1.5 \mathrm{Sr}$ substrate. The corrosion rate decreased with increasing immersion time for the $\mathrm{Sr}-\mathrm{P}$ coating samples and the as-extruded $\mathrm{Mg}-1.5 \mathrm{Sr}$ substrate samples, indicating a difference between the initial slow degradation and the subsequent somewhat slower corrosion. The MAO coating samples had the lowest corrosion rate for immersion of 3 days, and a somewhat higher corrosion rate for immersion of 7 days, and then somewhat lower corrosion rate for immersion of 14 days. To allow easy comparison, the corrosion rates evaluated from weight loss measurement after immersion of 3, 7 and 14 days of the as-cast $\mathrm{Mg}-1.5 \mathrm{Sr}$ substrate and its different coatings are shown in Fig. 6b. The as-cast $\mathrm{Mg}-\mathrm{Sr}$ alloy and the coated as-cast $\mathrm{Mg}-\mathrm{Sr}$ alloy exhibit higher corrosion rate in comparison with the as-extruded $\mathrm{Mg}-\mathrm{Sr}$ alloy and the corresponding coated as-extruded $\mathrm{Mg}-\mathrm{Sr}$ alloy, indicating that the corrosion properties of the coated samples depend on their substrates.

Figure 7 shows the corroded cross-sectional morphologies of the different samples after immersion in Hanks' 

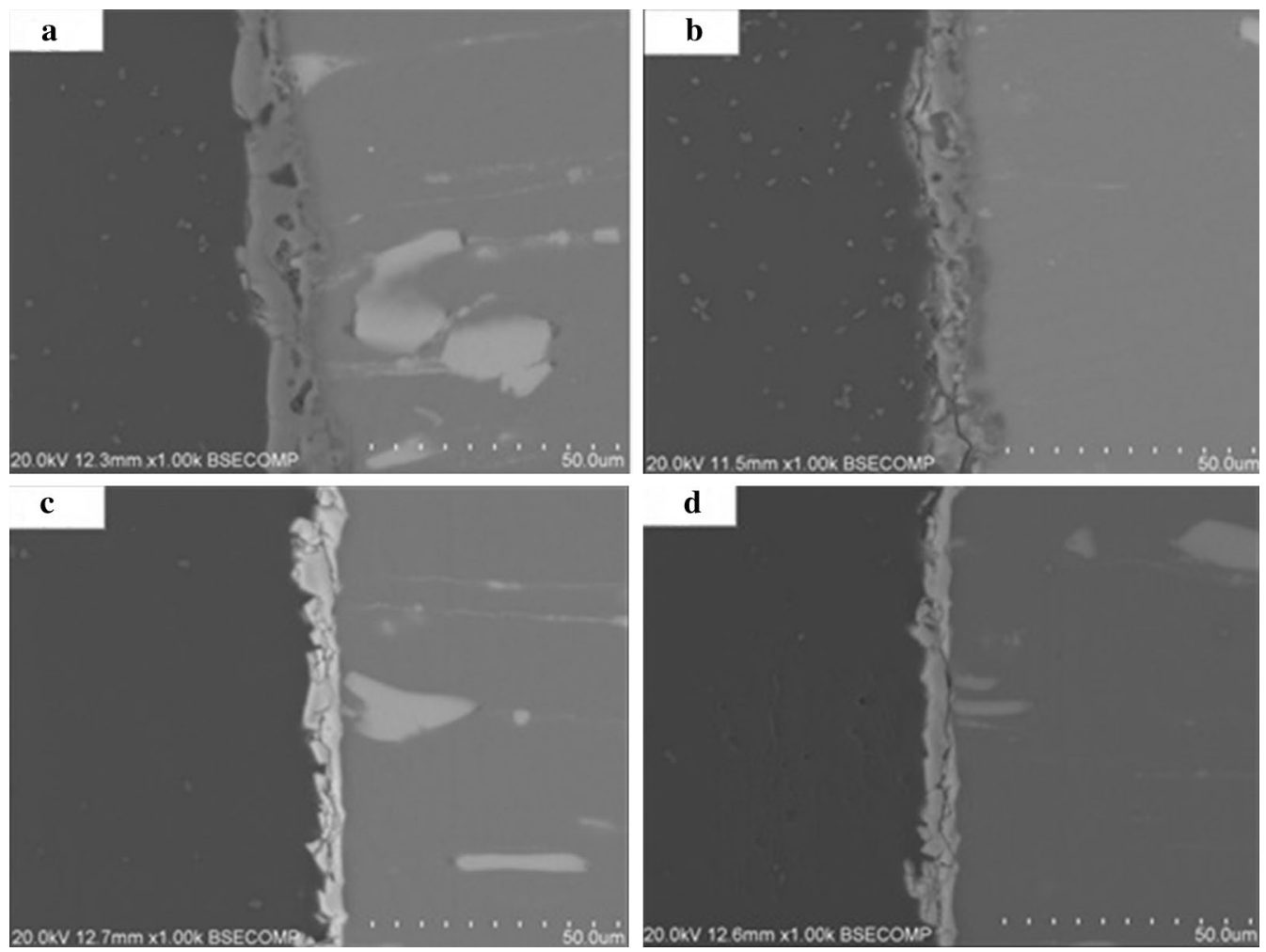

Fig. 7 Cross-sectional morphologies of MAO coating (a 7 d, b 14 d) and Sr-P coating (c 7 d, d 14 d) after immersion

solution of 7 and 14 days. The thickness of the MAO coating after immersion of 7 days was $10 \mu \mathrm{m}$ to $18 \mu \mathrm{m}$, and the coating was continuous (Fig. 7a). After immersion of 14 days, the thickness of MAO coating was $8 \mu \mathrm{m}$ to $14 \mu \mathrm{m}$. Compared with the immersion of 7 days, the thickness decreased slightly. Furthermore, the crack in the MAO coating propagated and the corrosion became more severe (Fig. 7b). The thickness of Sr-P coating was 5-9 $\mu \mathrm{m}$ after immersion of 7 days (Fig. 7c). After immersion of 14 days, the thickness of Sr-P coating was 4-7 $\mu \mathrm{m}$. Compared with the immersion of 7 days, the thickness decreased slightly and the cracks in the Sr-P coating propagated to the substrate (Fig. 7d).

EDS analysis as shown in Fig. 8 was used to evaluate the elemental compositions of the coatings after immersion of 7 and 14 days. The cross section of MAO coating after immersion of 7 days was mainly composed of elements of $\mathrm{O}, \mathrm{F}, \mathrm{Ca}, \mathrm{P}$ and $\mathrm{Mg}$ (Fig. 8a). Compared with the chemical composition of original MAO coating, the content of elements of $\mathrm{Mg}, \mathrm{Ca}$ and $\mathrm{P}$ increased. The cross section of MAO coating after immersion of 14 days was still mainly composed of elements of $\mathrm{O}, \mathrm{F}, \mathrm{Ca}, \mathrm{P}$ and $\mathrm{Mg}$ (Fig. 8b). Compared with immersion of 7 days, the content of elements of $\mathrm{Mg}, \mathrm{Ca}$ and $\mathrm{P}$ continued to increase. The cross section close to the substrate of MAO coating after immersion of 14 days was mainly composed of elements of $\mathrm{O}, \mathrm{Mg}$ and $\mathrm{P}$ (Fig. 8c). The above results indicated that during the degradation of MAO coating, the corrosion product of $\mathrm{Mg}(\mathrm{OH})_{2}$ formed close to the matrix. Meanwhile, elements of $\mathrm{Ca}$ and $\mathrm{P}$ were not only deposited on the coating surface, but also distributed in the degradation products. $\mathrm{Ca}-\mathrm{P}$ deposition increased with increasing immersion time. The cross section of $\mathrm{Sr}-\mathrm{P}$ coating after immersion of 7 days was mainly composed of elements of $\mathrm{O}, \mathrm{Sr}, \mathrm{P}$ and $\mathrm{Mg}$ (Fig. 8d). Compared with the chemical composition of original Sr-P coating, the content of elements of $\mathrm{Mg}, \mathrm{Sr}$ and $\mathrm{P}$ increased. The cross section close to the substrate of $\mathrm{Sr}-\mathrm{P}$ coating after immersion of 7 days was mainly composed of elements of $\mathrm{O}$ and $\mathrm{Mg}$ (Fig. 8e), which indicated that a layer of corrosion product of $\mathrm{Mg}$ $(\mathrm{OH})_{2}$ formed on the surface of $\mathrm{Sr}-\mathrm{P}$ coating. The cross section of $\mathrm{Sr}-\mathrm{P}$ coating after immersion of 14 days was still mainly composed of elements of $\mathrm{O}, \mathrm{Sr}, \mathrm{P}$ and $\mathrm{Mg}$ (Fig. 8f). Compared with immersion of 7 days, the content of elements of $\mathrm{Mg}$ and $\mathrm{P}$ continued to increase, revealing that the phosphate degradation products formed when the $\mathrm{Sr}-\mathrm{P}$ coated samples were immersed in solution. To allow easy comparison, Table 4 presents the average chemical compositions obtained from at least three spot sites using EDS of the coatings after immersion of 7 and 14 days. 

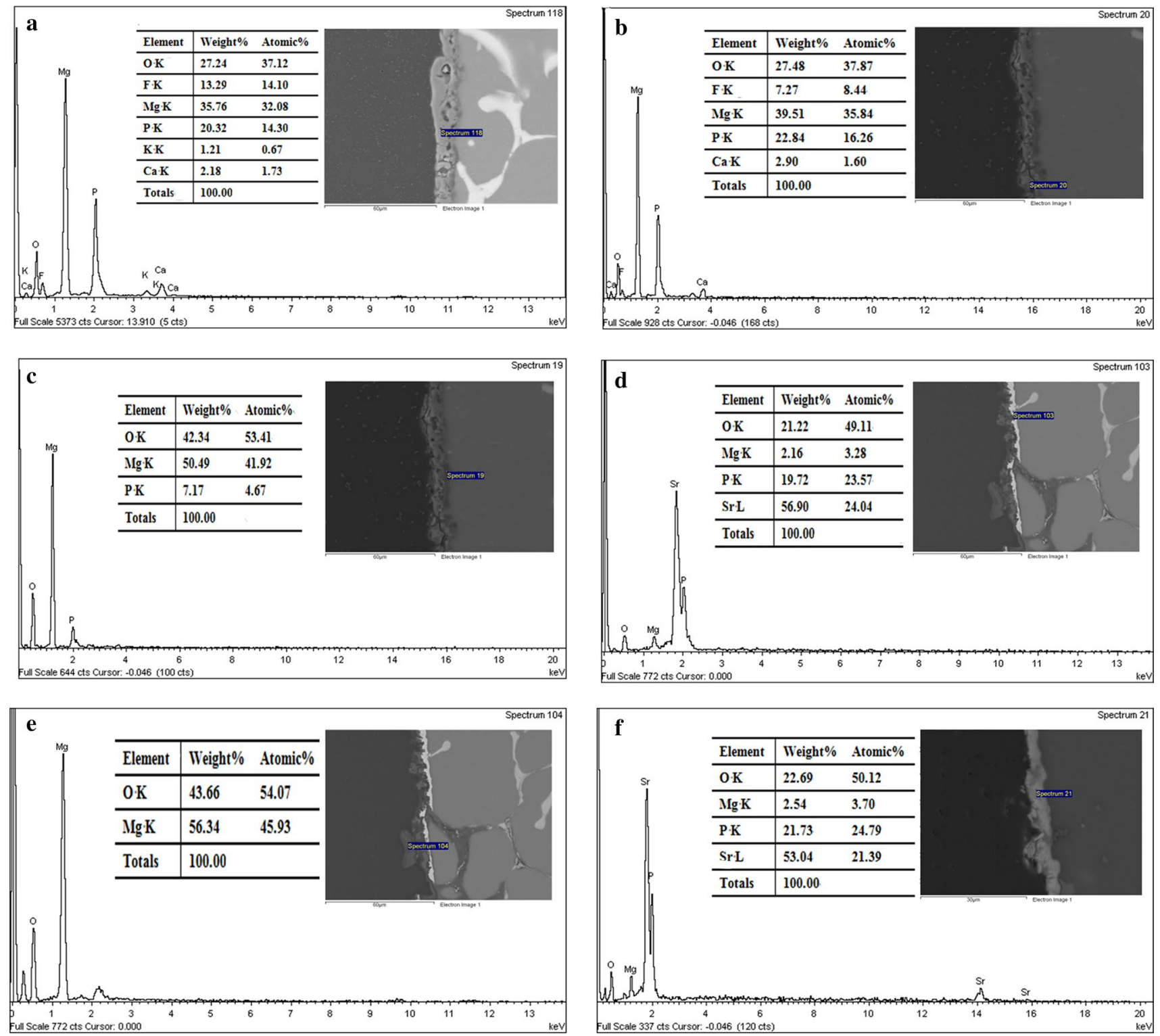

Fig. 8 EDS spectra after immersion for MAO coating in a cross section for $7 \mathrm{~d}$; $\mathbf{b}$ cross section for $14 \mathrm{~d}$; $\mathbf{c}$ cross section close to substrate for 14 $\mathrm{d}$ and $\mathrm{Sr}-\mathrm{P}$ coating in $\mathbf{d}$ cross section for $7 \mathrm{~d}$; e cross section close to substrate for $7 \mathrm{~d}$; $\mathbf{f}$ cross section for $14 \mathrm{~d}$

\section{Discussion}

\subsection{Formation Mechanism of MAO Coating and Sr-P Coating}

The compositional and phase investigations by means of EDS (Table 1) and XRD (Fig. 4a) reveal that the MAO coating on the as-extruded $\mathrm{Mg}-1.5 \mathrm{Sr}$ alloy was composed of $\mathrm{MgO}$ and elements of $\mathrm{Ca}$ and $\mathrm{P}$ in an amorphous state. The formation mechanism of MAO coating can be divided into four stages [35]. Firstly, plenty of small gas bubbles occurred on the sample surface and a thin oxide film formed during the first few seconds of oxidation. Secondly, with increasing voltage, dielectric breakdown of the oxide film occurred and the oxide film thickened at locations of breakdown. Thirdly, pores in the oxide layer formed due to the bubbles embedded in the coating. Fourthly, the discrete larger sparks and breakdown channels formed, leading to many micro-pores.

The compositional and phase investigations by means of EDS (Table 1) and XRD (Fig. 4b) reveal that $\mathrm{SrHPO}_{4}$ was the primary constituent of the $\mathrm{Sr}-\mathrm{P}$ coating on the asextruded $\mathrm{Mg}-1.5 \mathrm{Sr}$ alloy, along with $\mathrm{Mg}_{3}\left(\mathrm{PO}_{4}\right)_{2}$ phase in minor quantity. The atomic ratio of $\mathrm{Sr}$ and $\mathrm{P}$ was approximately 1.0 , which indicated that the reaction product was $\mathrm{SrHPO}_{4}$. This can be understood by the following reactions between as-extruded $\mathrm{Mg}-1.5 \mathrm{Sr}$ alloy and the conversion 
Table 4 Chemical compositions of the coatings after immersion of 7 and 14 days

\begin{tabular}{|c|c|c|c|c|c|c|c|c|}
\hline Coating & & $\mathrm{Mg}$ & $\mathrm{O}$ & F & $\mathrm{P}$ & $\mathrm{K}$ & $\mathrm{Ca}$ & $\mathrm{Sr}$ \\
\hline \multirow[t]{2}{*}{ MAO: cross section-7 d } & wt $\%$ & $36 \pm 3$ & $27 \pm 2$ & $13 \pm 1$ & $20 \pm 2$ & $1.2 \pm 0.1$ & $2.2 \pm 0.1$ & \\
\hline & at. $\%$ & $32 \pm 3$ & $37 \pm 4$ & $14 \pm 1$ & $14 \pm 1$ & $0.7 \pm 0.1$ & $1.7 \pm 0.1$ & \\
\hline \multirow[t]{2}{*}{ MAO: cross section-14 d } & $\mathrm{wt} \%$ & $40 \pm 4$ & $28 \pm 3$ & $7.3 \pm 0.4$ & $23 \pm 3$ & & $2.9 \pm 0.1$ & \\
\hline & at. $\%$ & $36 \pm 4$ & $38 \pm 3$ & $8.4 \pm 0.4$ & $16 \pm 1$ & & $1.6 \pm 0.1$ & \\
\hline \multirow{2}{*}{$\begin{array}{l}\text { MAO: cross section-14 d } \\
\text { Close to the substrate }\end{array}$} & $\mathrm{wt} \%$ & $51 \pm 4$ & $42 \pm 4$ & & $7.2 \pm 0.3$ & & & \\
\hline & at. $\%$ & $42 \pm 3$ & $53 \pm 4$ & & $4.7 \pm 0.3$ & & & \\
\hline \multirow[t]{2}{*}{ Sr-P: cross section-7 d } & wt $\%$ & $2.2 \pm 0.1$ & $21 \pm 2$ & & $20 \pm 2$ & & & $57 \pm 4$ \\
\hline & at. $\%$ & $3.3 \pm 0.1$ & $49 \pm 3$ & & $24 \pm 3$ & & & $24 \pm 2$ \\
\hline \multirow{2}{*}{$\begin{array}{l}\text { Sr-P: cross section- } 7 \mathrm{~d} \\
\text { Close to the substrate }\end{array}$} & $\mathrm{wt} \%$ & $56 \pm 4$ & $44 \pm 4$ & & & & & \\
\hline & at. $\%$ & $46 \pm 3$ & $54 \pm 4$ & & & & & \\
\hline \multirow[t]{2}{*}{$\mathrm{Sr}-\mathrm{P}$ : cross section-14 d } & wt $\%$ & $2.6 \pm 0.1$ & $23 \pm 2$ & & $22 \pm 1$ & & & $53 \pm 4$ \\
\hline & at. $\%$ & $3.7 \pm 0.1$ & $50 \pm 4$ & & $25 \pm 2$ & & & $21 \pm 2$ \\
\hline
\end{tabular}

coating solution (Eqs. 1-5). When the as-extruded Mg$1.5 \mathrm{Sr}$ alloy was immersed in the mixed solution containing $\mathrm{Sr}\left(\mathrm{NO}_{3}\right)_{2}$ and $\mathrm{NH}_{4} \mathrm{H}_{2} \mathrm{PO}_{4}$, the $\mathrm{H}_{2} \mathrm{PO}_{4}{ }^{-}$anions being the high acid radical anions, easily reacted with $\mathrm{Mg}$. The $\mathrm{Mg}$ substrate dissolved and released a large amount of $\mathrm{Mg}^{2+}$ cations, hydrogen phosphate $\left(\mathrm{HPO}_{4}{ }^{2-}\right)$ anions and $\mathrm{H}_{2}$ gas, resulting in an increase in the alkalinity of the solution, which promoted the $\mathrm{H}_{2} \mathrm{PO}_{4}{ }^{-}$anions ionized to generate $\mathrm{HPO}_{4}{ }^{2-}$ anions. The $\mathrm{HPO}_{4}{ }^{2-}$ anions reacted with the $\mathrm{Sr}^{2+}$ to form the $\mathrm{SrHPO}_{4}$ precipitation. As the reaction was occurring, the hydrogen ion was consumed continuously and the alkalinity of the solution was increased, and $\mathrm{Mg}_{3}\left(\mathrm{PO}_{4}\right)_{2}$ was formed as follows:

$$
\begin{aligned}
& \mathrm{Mg}+2 \mathrm{H}_{2} \mathrm{PO}_{4}^{-}=\mathrm{Mg}^{2+}+2 \mathrm{HPO}_{4}^{2-}+\mathrm{H}_{2} \uparrow, \\
& \mathrm{H}_{2} \mathrm{PO}_{4}^{-}=\mathrm{HPO}_{4}^{2-}+\mathrm{H}^{+}, \\
& \mathrm{Sr}^{2+}+\mathrm{HPO}_{4}^{2-}=\mathrm{SrHPO}_{4} \downarrow, \\
& \mathrm{HPO}_{4}^{2-}=\mathrm{PO}_{4}^{3-}+\mathrm{H}^{+}, \\
& 2 \mathrm{PO}_{4}^{3-}+3 \mathrm{Mg}^{2+}=\mathrm{Mg}_{3}\left(\mathrm{PO}_{4}\right)_{2} \downarrow .
\end{aligned}
$$

\subsection{In Vitro Degradation Behaviors of Bare, MAO-Coated and Sr-P Coated As-Extruded Condition}

Considering as-extruded $\mathrm{Mg}-1.5 \mathrm{Sr}$ substrate, much $\mathrm{Mg}(\mathrm{OH})_{2}$ was formed due to the dissolution of $\mathrm{Mg}$, and then the $\mathrm{Cl}^{-}$in the solution would gradually transform the $\mathrm{Mg}(\mathrm{OH})_{2}$ into the soluble $\mathrm{MgCl}_{2}$. The corrosion rate for asextruded $\mathrm{Mg}-1.5 \mathrm{Sr}$ substrate after immersion of three days was relatively high. Then the decline of the corrosion rate was owing to the precipitation of corrosion products such as $\mathrm{Mg}(\mathrm{OH})_{2}$ and the $\mathrm{Ca}^{2+}$ ions, $\mathrm{SO}_{4}^{2-}$ ions, $\mathrm{H}_{2} \mathrm{PO}_{4}^{-}$ions, $\mathrm{HPO}_{4}^{2-}$ ions and $\mathrm{HCO}_{3}^{-}$ions in the Hanks' solution inhibited the corrosion of $\mathrm{Cl}^{-}$to some extent $[36,37]$. In addition, during the subsequent immersion time, the successive decrease in the corrosion rate should be attributed to the formation and dissolution of the corrosion product layer [38, 39].

The corrosion rate of $\mathrm{Sr}-\mathrm{P}$ coating was basically consistent with that of the extruded Mg-1.5Sr substrate. During the early stage of immersion, the $\mathrm{Sr}-\mathrm{P}$ coating contained some defects which permitted some corrosive media penetrating to the substrate, thus leading to the formation of corrosion products of $\mathrm{Mg}(\mathrm{OH})_{2}$ at the interface as well as the release of $\mathrm{OH}^{-}$. Additionally, due to the poor chemical stability of $\mathrm{SrHPO}_{4}$ in an alkaline environment, a substantial amount of the $\mathrm{Sr}-\mathrm{P}$ coating dissolved, and the thickness of the $\mathrm{Sr}-\mathrm{P}$ coating decreased. As a consequence, the corrosion rate after immersion of three days was only somewhat lower than that of the as-extruded $\mathrm{Mg}-\mathrm{Sr}$ alloy. However, with the increase in the amount of corrosion products, which retarded the further dissolution of the substrate, the degradation rate of the samples gradually decreased.

When the as-extruded Mg-1.5Sr alloy with MAO coating was immersed in Hanks' solution, its degradation behavior was as follows. At the beginning, the corrosion medium penetrated through defects in the outer porous layer of the MAO coating to make contact with the inner layer of the coating, resulting in the degradation of the inner layer. Meantime, the outer porous layer of the MAO coating was thoroughly exposed to the corrosive medium. The $\mathrm{MgO}$ in the coating was gradually hydrated to form $\mathrm{Mg}(\mathrm{OH})_{2}$, and the substrate was directly corroded. The $\mathrm{Mg}(\mathrm{OH})_{2}$ reacted with the constituents of the corrosive medium to form some precipitates. The corrosion rate of the substrate after three days was at a low level. However, with the ongoing immersion, the degradation of the outer porous layer induced some defects and enlarged the existing ones, which accelerated of the substrate degradation. Meanwhile, an increasing number of precipitates of $\mathrm{Ca}$ and $\mathrm{P}$ were deposited on the coating (Table 4) and these corrosion products were formed at the 
substrate-coating interface, which retarded the degradation of the substrate. The outer porous layer experienced destruction and restoration alternately, whereas the inner compact layer only experienced destruction. The corrosion rate of the substrate after immersion of 7 days increased slightly, owing to the higher destruction rate of the inner dense layer than that of the deposition layer, but nevertheless was substantially lower than the corrosion rate of the as-extruded substrate. When the corrosion continued, the corrosion rate decreased after immersion of 14 days because of more consumption of the MAO coating and more accumulation of the deposition and corrosion product.

\subsection{The Comparison of the Protection Properties Between the Sr-P Coating and MAO Coating on the As-Extruded Condition}

The immersion and electrochemical corrosion evaluation indicates that the MAO coating and the conversion $\mathrm{Sr}-\mathrm{P}$ coating could retard the degradation of the as-extruded $\mathrm{Mg}$ $1.5 \mathrm{Sr}$ alloy in Hanks' solution. The protection efficacy of the MAO coating was higher than that of the Sr-P coating. It was reported that the ability of coatings to protect magnesium alloys depended on the thickness, compactness and phase composition of the coatings [40]. Since $\mathrm{MgO}$ phase is not stable in the neutral electrolyte, it will degrade to generate $\mathrm{Mg}(\mathrm{OH})_{2}$. The corrosion product of $\mathrm{Mg}(\mathrm{OH})_{2}$ can protect the $\mathrm{Mg}-1.5 \mathrm{Sr}$ substrate to some extent. It has been reported that $\mathrm{SrHPO}_{4}$ is not stable in the alkaline solution. Although the original thickness of the MAO coating (about 13-18 $\mu \mathrm{m}$ ) was thinner than that of the $\mathrm{Sr}-\mathrm{P}$ coating (about $25-40 \mu \mathrm{m})$, the MAO coating was thicker than that of the Sr-P coating after immersion of 7 and 14 days, which is related to the dissolution or transformation of $\mathrm{SrHPO}_{4}$ from $\mathrm{Sr}-\mathrm{P}$ coating into more unstable corrosion products. As a result, the protection property of MAO coating is superior to that of $\mathrm{Sr}-\mathrm{P}$ coating.

It can be seen that the original $\mathrm{Sr}-\mathrm{P}$ coating is uneven (Fig. 2d). With increasing immersion time, cracks in the $\mathrm{Sr}-\mathrm{P}$ coating gradually propagated to the substrate (Fig. 7c, d), resulting in the decrease in the binding strength between the coating and the substrate. The sites with relatively thin coating were easily eroded off, leading to the substrate exposed to the corrosion medium. Due to the galvanic corrosion between the exposed substrate and the coated substrate, the substrate with the coating damage accelerated degradation after the Sr-P coating scaled off locally, resulting in some local corrosion. Due to the difference in molar volume between the corrosion products and substrate under the coating, a stress on the coating formed, which caused some coating to scale off before being completely degraded [41]. The MAO coating was composed of the inner compact layer and outer porous layer, in which the adhesion between the inner layer and the matrix was good, and the inner compact layer could retard the corrosion of matrix. In addition, a $\mathrm{Ca}-\mathrm{P}$ deposition layer in the MAO coating formed on the surface, which separated the substrate from the corrosive medium in a certain extent, and thereby delayed the corrosion of the substrate. Therefore, the corrosion resistance of MAO coating is better than that of $\mathrm{Sr}-\mathrm{P}$ coating.

\subsection{The Role of Substrate Microstructure on Corrosion Resistance}

The corrosion properties of the coated samples were dependent on their substrates. In comparison with the bare and coated as-cast conditions, the corresponding bare and coated as-extruded conditions showed much better corrosion resistance, which might be correlated with the nature of the substrates. As shown in Fig. 1, different from the broken discontinuous fine second-phase particles distributed along the grain boundaries in the as-extruded condition, the second phases were located clearly along the grain boundary in the as-cast condition, showing a somewhat netlike continuous distribution. For the as-cast condition, the grain boundaries with the distribution of the second phases accelerated the galvanic corrosion of the substrate due to the penetration of the electrolytes into the coating as the samples were exposed to the immersion fluid. As a result, more serious local corrosion occurred and it was more difficult to achieve a stable interface for the as-cast condition due to the more severe galvanic corrosion. Particularly, the grain boundaries with the distribution of second phases corroded quickly. The corrosion products were left at the grain boundaries, which could destroy the substrate-coating interface. The corrosion became severe at the grain boundary where it was gradually evolved into the corrosion channel, resulting in the broken substrate and interface. Partial fragments of coating peeled off from the substrate and accordingly the coating was mostly destroyed with the advance of corrosion. The substrate corroded severely due to the failure of coating and the deposition of corrosion products on the surface. The coatings peeled off from the substrate before being completely dissolved because the corrosion products of the substrate beneath the coating would generate a force on the coating due to their different molar volume [42, 43]. Subsequently, the corrosion became severe at the grain boundary where it was gradually evolved into the corrosion channel, finally resulted in the completely destruction of grain boundaries and even the fracture of the substrate. In contrast, the finer microstructure of the as-extruded alloy corroded much slower, because there was much less effective microgalvanic corrosion. For the as-extruded alloy, there was a significant decrease in the corrosion rate by both coatings, with much better performance shown by the MAO coating. 


\section{Conclusions}

1. The corrosion resistance of the coated $\mathrm{Mg}-1.5 \mathrm{Sr}$ alloy was dependent on the coating itself and on the microstructure condition of the substrate. For the as-cast condition and the as-extruded condition, there was a significant decrease in the corrosion rate by both the $\mathrm{Sr}-\mathrm{P}$ coating and the MAO coatings, with much better performance shown by the MAO coating. Compared to that of the as-cast condition, the finer microstructure of the substrate of the as-extruded condition corroded much slower.

2. Microstructure and composition of the coatings obtained by micro-arc oxidation and phosphate conversion technique were distinctly different, which were related to their biodegradable behavior.

3. As-extruded Mg-1.5Sr alloy that was coated by microarc oxidation technique or phosphate conversion technique exhibited better corrosion resistance than the uncoated as-extruded $\mathrm{Mg}-1.5 \mathrm{Sr}$ alloy. Furthermore, asextruded $\mathrm{Mg}-1.5 \mathrm{Sr}$ alloy coated by micro-arc oxidation technique presented better corrosion resistance, i.e., the corrosion resistance was ranked in the following order: $\mathrm{MAO}>\mathrm{Sr}-\mathrm{P}>$ as-extruded $\mathrm{Mg}-1.5 \mathrm{Sr}$ substrate.

Acknowledgements The study was financially supported by the National Natural Science Foundation of China (No. 51874368).

\section{References}

[1] C. Wang, H.T. Yang, X. Li, Y.F. Zheng, J. Mater. Sci. Technol. 32, 909 (2016)

[2] Y.B. Zhao, L.Q. Shi, L.Y. Cui, C.L. Zhang, S.Q. Li, R.C. Zeng, F. Zhang, Z.L. Wang, Acta Metall. Sin. (Engl. Lett.) 31, 180 (2018)

[3] R.C. Zeng, L.J. Liu, S.Q. Li, Y.H. Zou, F. Zhang, Y.N. Yang, H.Z. Cui, E.H. Han, Acta Metall. Sin. (Engl. Lett.) 26, 681 (2013)

[4] A. Atrens, G.L. Song, M. Liu, Z. Shi, F. Cao, M.S. Dargusch, Adv. Eng. Mater. 17, 400 (2015)

[5] W. Zhang, L.L. Tan, D.R. Ni, J.X. Chen, Y.C. Zhao, L. Liu, C.J. Shuai, K. Yang, A. Atrens, M.C. Zhao, J. Mater. Sci. Technol. 35, 777 (2019)

[6] R. Xu, M.C. Zhao, Y.C. Zhao, L. Liu, C. Liu, C.D. Gao, C.J. Shuai, A. Atrens, Mater. Lett. 237, 253 (2019)

[7] X.D. Yan, P. Wan, L.L. Tan, M.C. Zhao, L. Qin, K. Yang, Mater. Sci. Eng. C 93, 565 (2018)

[8] X.D. Yan, P. Wan, L.L. Tan, M.C. Zhao, C. Shuai, K. Yang, Mater. Sci. Eng. B 229, 105 (2018)

[9] J. Buehler, P. Chappuis, J.L. Saffar, Y. Tsouderos, A. Vignery, Bone 29, 176 (2001)

[10] C.J. Chung, H.Y. Long, Acta Biomater. 7, 4081 (2011)

[11] W.D. Wang, J.J. Han, X. Yang, M. Li, P. Wan, L.L. Tan, Y. Zhang, K. Yang, Mater. Sci. Eng. B 214, 26 (2016)
[12] Y. Shangguan, P. Wan, L.L. Tan, X.M. Fan, L. Qin, K. Yang, J. Colloid Interface Sci. 481, 1 (2016)

[13] C. Liu, P. Wan, L. Tan, K. Wang, K. Yang, J. Orthop. Transl. 2, 139 (2014)

[14] J. Han, P. Wan, Y. Ge, X. Fan, L. Tan, J. Li, K. Yang, Mater. Sci. Eng. C 58, 799 (2016)

[15] Y. Shangguan, L. Sun, P. Wan, L. Tan, C. Wang, X. Fan, L. Qin, K. Yang, Mater. Sci. Eng. C 69, 95 (2016)

[16] H.S. Brar, J. Wong, M.V. Manuel, J. Mech. Behav. Biomed. 7, 87 (2012)

[17] Y. Li, C. Wen, D. Mushahary, R. Sravanthi, N. Harishankar, G. Pande, P. Hodgson, Acta Biomater. 3177, 8 (2012)

[18] R.V. Suganthi, K. Elayaraja, M.I. Ahymah Joshy, V. Sarath Chandra, E.K. Girija, S. Narayana Kalkura, Mater. Sci. Eng. C 31, 593 (2011)

[19] M. Bornapour, N. Muja, D. Shum-Tim, M. Cerruti, M. Pekguleryuz, Acta Biomater. 9, 5319 (2013)

[20] L.Y. Cui, S.D. Gao, P.P. Li, R.C. Zeng, F. Zhang, S.Q. Li, E.H. Han, Corros. Sci. 118, 84 (2017)

[21] R.C. Zeng, L.Y. Cui, K. Jiang, R. Liu, B.D. Zhao, Y.F. Zheng, A.C.S. Appl, Mater. Interfaces 8, 10014 (2016)

[22] X.B. Chen, D.R. Nisbet, R.W. Li, P.N. Smith, T.B. Abbott, M.A. Easton, D.H. Zhang, N. Birbilis, Acta Biomater. 10, 1463 (2014)

[23] C. Liu, Q. Shi, W. Yan, C. Shen, K. Yang, Y. Shan, M. Zhao, J. Mater. Sci. Technol. 35, 266 (2019)

[24] M.C. Zhao, Y. Deng, X. Zhang, Scr. Mater. 58, 560 (2008)

[25] F. Cao, Z. Shi, G.L. Song, M. Liu, M.S. Dargusch, A. Atrens, Corros. Sci. 90, $176(2015)$

[26] T.H. Van Steenkiste, J.R. Smith, R.E. Teets, Surf. Coat. Technol. 154, 237 (2002)

[27] T. Fu, Z.F. Zhou, Y.M. Zhou, X.D. Zhu, Q.F. Zeng, C.P. Wang, K.Y. Li, J. Lu, Surf. Coat. Technol. 207, 555 (2012)

[28] W.X. Li (ed.), Magnesium and Magnesium Alloys (First Edition in 2005) (Central South University Press, Changsha, 2005), p. 47

[29] Z. Yao, L. Li, Z. Jiang, Appl. Surf. Sci. 255, 6724 (2009)

[30] M.C. Zhao, M. Liu, G.L. Song, A. Atrens, Corros. Sci. 50, 3168 (2008)

[31] M.C. Zhao, M. Liu, G.L. Song, A. Atrens, Adv. Eng. Mater. 10, 93 (2008)

[32] G.L. Makar, J. Kruger, A. Joshi, in Advances in Magnesium Alloys and Composites, ed. by H.G. Paris, W.H. Hunt (TMS, Warrendale, 1988)

[33] S. Virtanen, Mater. Sci. Eng. B 20, 1600 (2011)

[34] M.C. Zhao, P. Schmutz, S. Brunner, M. Liu, G.L. Song, A. Atrens, Corros. Sci. 51, 1277 (2009)

[35] L. Wang, L. Chen, Z. Yan, W. Fu, Appl. Surf. Sci. 205, 1651 (2010)

[36] G. Song, D. Stjohn, Corros. Sci. 46, 1381 (2004)

[37] Y.C. Zhao, M.C. Zhao, R. Xu, L. Liu, J.X. Tao, C. Gao, C. Shuai, A. Atrens, J. Alloys Compd. 770, 549 (2019)

[38] Y.J. Lu, L.L. Tan, H.L. Xiang, B.C. Zhang, K. Yang, Acta Metall. Sin. (Engl. Lett.) 25, 287 (2012)

[39] M.C. Zhao, M. Liu, G.L. Song, A. Atrens, Corros. Sci. 50, 1939 (2008)

[40] S. Hiromoto, M. Tomozawa, N. Maruyama, J. Mech. Behav. Biomed. Mater. 25, 1 (2013)

[41] Y.Q. Wang, M.Y. Zheng, K. Wu, Mater. Lett. 59, 1727 (2005)

[42] L.Y. Li, L.Y. Cui, B. Liu, R.C. Zeng, X.B. Chen, S.Q. Li, Z.L. Wang, E.H. Han, Appl. Surf. Sci. 465, 1066 (2019)

[43] L.Y. Li, L.Y. Cui, R.C. Zeng, S.Q. Li, X.B. Chen, Y.F. Zheng, M.B. Kannan, Acta Biomater. 79, 23 (2018) 